\title{
Corticosteroid Action in the Brain: The Potential of Selective Receptor Modulation
}

\author{
Eva M.G. Viho ${ }^{a, b}$ Jacobus C. Buurstede ${ }^{a, b}$ Ahmed Mahfouz ${ }^{c, d}$ \\ Lisa L. Koorneef ${ }^{a, b}$ Lisa T.C.M. van Weert ${ }^{a, b}$ René Houtman $^{e}$ Hazel J. Hunt ${ }^{f}$ \\ Jan Kroon ${ }^{a, b}$ Onno C. Meijer ${ }^{a, b}$ \\ ${ }^{a}$ Division of Endocrinology, Department Internal Medicine, Leiden University Medical Center, Leiden, \\ The Netherlands; ${ }^{b}$ Einthoven Laboratory for Experimental Vascular Medicine, Leiden University Medical Center, \\ Leiden, The Netherlands; ' Delft Bioinformatics Laboratory, Delft University of Technology, Delft, The Netherlands; \\ d Leiden Computational Biology Center, Leiden University Medical Center, Leiden, The Netherlands; \\ ePamGene BV, 's-Hertogenbosch, The Netherlands; ${ }^{\text {e }}$ Corcept Therapeutics, Menlo Park, CA, USA
}

\section{Keywords}

Glucocorticoid receptor - Learning and memory - Nuclear receptor coregulators - Neuropsychiatric diseases .

Neurodegenerative diseases

\begin{abstract}
Glucocorticoid hormones have important effects on brain function in the context of acute and chronic stress. Many of these are mediated by the glucocorticoid receptor (GR). GR has transcriptional activity which is highly context-specific and differs between tissues and even between cell types. The outcome of GR-mediated transcription depends on the interactome of associated coregulators. Selective GR modulators (SGRMs) are a class of GR ligands that can be used to activate only a subset of GR-coregulator interactions, thereby giving the possibility to induce a unique combination of agonistic and antagonistic GR properties. We describe SGRM action in animal models of brain function and pathology, and argue for their utility as molecular filters, to characterize context-specific GR interactome and tran-
\end{abstract}

scriptional activity that are responsible for particular glucocorticoid-driven effects in cognitive processes such as memory consolidation. The ultimate objective of this approach is to identify molecular processes that are responsible for adaptive and maladaptive effects of glucocorticoids in the brain.

(C) 2019 The Author(s) Published by S. Karger AG, Basel

\section{Stress and Glucocorticoids in Brain Function and Memory}

Stress, Homeostasis, and the Hypothalamic Pituitary Adrenal Axis

Stress is a state following a perceived threat to homeostasis. It involves the activation of several responsive systems, including the endocrine, nervous, and immune systems, altogether facilitating adaptation of the organism to the stressor [1]. More specifically, the stress response includes the central corticotropin-releasing hormone (CRH) system, the sympathetic nervous system, and the

\begin{tabular}{|c|c|}
\hline KARGER & $\begin{array}{l}\text { (c) } 2019 \text { The Author(s) } \\
\text { Published by S. Karger AG, Basel }\end{array}$ \\
\hline $\begin{array}{l}\text { E-Mail karger@karger.com } \\
\text { www.karger.com/nen }\end{array}$ & $\begin{array}{l}\text { This article is licensed under the Creative Commons Attribution- } \\
\text { NonCommercial-NoDerivatives } 4.0 \text { International License (CC BY- } \\
\text { NC-ND) (http://www.karger.com/Services/OpenAccessLicense). } \\
\text { Usage and distribution for commercial purposes as well as any dis- } \\
\text { tribution of modified material requires written permission. }\end{array}$ \\
\hline
\end{tabular}

Onno C. Meijer

Division of Endocrinology, Department of Internal Medicine Leiden University Medical Center

Albinusdreef 2, NL-2333 ZA Leiden (The Netherlands)

E-Mail o.c.meijer@lumc.nl 
hypothalamic pituitary adrenal (HPA) axis. The latter constitutes the main neuroendocrine effector of the stress response, in which the stressor triggers activity of the hypothalamic paraventricular nucleus (PVN). This initiates a cascade of hormonal processes starting with CRH release from the PVN, which in turn triggers production and release of adrenocorticotropic hormone from the anterior pituitary gland, ultimately resulting in the secretion of glucocorticoid (GC) hormones by the adrenal cortex into the circulation.

\section{Glucocorticoid Levels and Rhythm: From Adaptation to Maladaptation}

The predominant GC in humans is cortisol, while rodents exclusively produce corticosterone. Basal levels of GCs fluctuate as they display circadian and ultradian rhythms, which synchronize physiological processes and maintain appropriate stress responsiveness of the HPA axis and brain circuits [2-4]. The acute GC responses to stress, or short-term medical treatment with synthetic GCs, have many context-dependent effects that either curtail the initial stress response, exemplified by anti-inflammatory actions, or support prolonged redistribution of energy stores and adaptation to future stressors [5, 6]. Longterm and/or high exposure to endogenous and synthetic GCs is however associated with many adverse effects, including the development of metabolic diseases, osteoporosis, psychiatric symptoms, and cognitive deficits [7].

The brain is a prominent target of GCs, and it constitutes the central structure for adaptation to stress. GC effects on the brain are pleiotropic - as they influence behavior, cognition, mood, and programming of the stress response - all functions to adapt to stressors. Shifts in GC levels are associated with complex changes in neuronal activity that differ over time and according to the brain region examined [4]. At the cellular level, GCs are necessary for neuronal differentiation, integrity, growth, and synaptic and dendritic plasticity $[8,9]$. These cellular processes support brain functions such as decision-making, reward-based behavior, motor control, visual information processing, learning and memory, food intake, and energy regulation.

The interconnected limbic structures that mediate effects of stress and influence the HPA axis through PVNprojecting neurons are considered the main functional GC targets [10]. These include the medial prefrontal cortex (mPFC), the striatum, the hippocampus, and the amygdala. For example, stress impairs the long-term potentiation in projections from the basolateral amygdala to the prelimbic PFC and to the ventral hippocampus-
mPFC connection $[11,12]$. Acute GC treatment changes synaptic strength and excitability within hours, while repeated GC exposure or chronic stress paradigms consolidate such changes structurally via dendritic remodeling. This includes atrophy and reduction in apical spine density in the hippocampus region CA3 $[13,14]$ and the medial prefrontal pyramidal cells [15-17], but also increased dendritic complexity in, e.g., the amygdala [18].

The cellular basis for most GC effects in the brain is largely unknown. Below, we will argue that targeting specific processes downstream of GC receptor activation may be a good strategy to unravel these effects. Before we address this question, we will discuss general molecular mechanisms of corticosteroid receptor signaling as well as different types of ligands.

\section{The Receptors: Sensitivity of Brain Regions}

The effects of GCs are mediated by the GC receptor (GR) and the mineralocorticoid receptor (MR). These corticosteroid receptors are closely related members of the family of nuclear steroid receptors, which act as ligand-dependent transcription factors. They differ in tissue-distribution and ligand affinity [4]. MR is an aldosterone receptor in tissues that convert GCs into inactive metabolites, but in relation to the stress system, it acts as a receptor for cortisol and corticosterone. The high GC affinity of the MR results in its function as a sensor of basal GC levels, and its involvement in shaping the initial response to stress [19]. GR has a lower affinity [20] and is more ubiquitously expressed throughout the human body. The difference in affinity is about 10-fold, as is apparent from the pharmacological dissociation constants $\left(K_{d}\right)$ of $\sim 0.5 \mathrm{nM}$ for MR and $5 \mathrm{nM}$ for GR. GR therefore responds to elevated levels of GCs, i.e. during stress. Specifically in the brain, MR is mainly restricted to the hippocampus and other limbic areas, while GR is widely expressed. Within brain structures, different cell types show both qualitative and quantitative differences in their nuclear receptor expression profile. The use of single-cell profiling with RNA sequencing (scRNA-seq) allows large-scale comprehensive molecular classification of cell types in the brain and its subregions. For example, one study identified 69 different neuronal cell subtypes in the human temporal cortex [21]. These recent data suggest differential expression of GR in specific cell types in the human cortex, and also in hippocampal subregions [2123]. They also illustrate that scRNA-seq approaches can be used to identify specific cell types and intracellular pathways required for GC action in cognitive functions such as memory consolidation. 
After development of specific receptor (ant)agonists and the discovery of the two corticosteroid receptor types in the brain, it became clear GCs are essential for memory formation and each receptor type plays a distinctive role. For example, GR blockade shortly after learning interferes with long-term memory consolidation, while MR blockade interfered with response strategy in novel situations [24]. Later studies using GR dimerization-deficient mice confirmed these pharmacological experiments and established the necessity of genomic GR action in memory consolidation [25]. Likely, there is also a role for early, nongenomic effects of GCs in the promotion of memory formation ("encoding"). The formation and consolidation of spatial and declarative memory heavily rely on hippocampal physiology and synaptic plasticity, for instance via the modulation of glutamatergic transmission [26-28]. More recent work has also established roles of GR and MR in other, nonspatial, learning tasks; for example memory retrieval is impaired by prior exposure to GCs [29]. The suppressive effects on memory retrieval may be turned into use for treatment of post-traumatic stress disorder, anxiety, and phobic disorders [30, 31].

Processes that depend on GR are recapitulated, or exaggerated, by the use of synthetic GR agonists (like dexamethasone and prednisone), which are the mainstay in the treatment of inflammatory diseases, autoimmune disorders and hematologic cancers [3, 32]. The often maladaptive effects associated with excessive GC exposure include increased food intake and weight gain [33], disturbance of awakening/sleeping rhythm [8], anxiety, depression [34], and impaired cognitive functions [7].

Neuropsychiatric side effects after synthetic GC treatment may be the result of GR hyperactivation, but there is also evidence that implicates MR hypoactivation. GRspecific agonists suppress endogenous cortisol production through GR-mediated negative feedback on the HPA axis, which results in diminished MR activity that can be restored by exogenous cortisol treatment $[35,36]$. Nevertheless, GR antagonists are widely considered to counteract the adverse consequences of endogenous GC exposure, and may be considered for clinical use in some brain diseases, for instance in depression $[37,38]$, alcohol addiction [39], and neurodegenerative disease [40].

Since the classical GR antagonist RU486 also binds to progesterone and androgen receptors [41], efforts have been made to develop more selective GR antagonists. ORG34850 was shown to inhibit GR-mediated negative feedback on the HPA axis and was therefore considered to be a potential treatment for mood disorders (as dysfunctional HPA axis is known to be involved in depres- sion) [42]. More recently, the selective GR antagonist CORT113176 was shown to be efficacious in a model for alcohol seeking and self-administration in alcohol-dependent rats [39].

Thus, GR agonists and antagonists may help to understand which processes involve GR and may be used to counteract maladaptive consequences of GR overactivation. However, they will activate or antagonize all GRmediated effects, and given the pleiotropic nature of GR signaling, this may also trigger unwanted activities. There are additional types of ligands, called "dissociated ligands" or selective GR modulators (SGRMs) that activate only a subset of GR-dependent signals in the cell $[43,44]$. These may not only be advantageous in clinical settings, but they are also very promising tools to identify the cellular mechanisms underlying the many different effects of GCs in the brain.

\section{GR-Mediated Transcription}

Nongenomic effects notwithstanding [45], GR is best understood as ligand-dependent transcriptional factor. The receptor binds directly to DNA via its central DNA binding domain to inverted-repeat GC responsive elements (GREs) or to half-site DNA sequences, which mainly leads to upregulation of gene transcription [46]. This mechanism is shared with the other steroid receptors. Direct DNA occupancy of GR can also lead to the repression of target genes via so-called negative GREs [47, 48]. DNA binding often occurs in conjunction with other transcription factors and is typically followed by recruitment of coregulator proteins that either stimulate or repress transcription [49]. Additionally, GR can indirectly mediate transcription by inducing protein-protein interactions with other transcriptional factors already bound to DNA-specific loci [50]. One well-known example is the repressive cross-talk between GR and proinflammatory transcription factor AP-1 [51, 52].

\section{GR Genomic Occupancy in the Hippocampus}

Chromatin immunoprecipitation followed by sequencing (ChIP-seq) can be used to identify GR-occupied genomic regions in vivo, which can differ between species, tissues, cell types, and physiological state. In the rat hippocampus, GR signaling is mostly dependent on direct DNA binding. In 2013, Polman et al. [53] identified almost 2,500 genomic GR binding sites (GBS) with ChIPseq in rat hippocampus. Almost all these GBS contained a GRE. More recently, it has been confirmed that $89.9 \%$ 
of hippocampal GBS contained full or half GREs [54, 55]. Because ChIP-seq has only been performed on whole hippocampus homogenate, it is possible that protein-protein interactions in subsets of activated neurons have been overlooked. Nevertheless, these results show that direct DNA binding is a major mechanism contributing to GR activity in the hippocampus. The context (e.g., cell type) dependence of GRE-driven targets is apparent from the specific association of GR binding with other transcription factors, such as Nuclear Factor-1 [53-55]. Likely, GR can also heterodimerize with MR at a subset of binding sites $[55,56]$.

\section{Chromatin Remodeling}

GR transcriptional activity is regulated at different levels, starting with the organization of the nuclear chromatin and the availability of GREs for binding of the receptors. Gene transcription is orchestrated by nucleosome architecture and chromatin configuration. Both levels are further coordinated by genomic and epigenomic mechanisms that give dynamics to the chromosome layout and thereby modulate its accessibility. It has been shown that cell-specific GR-DNA interaction patterns are predetermined by cell-specific differences in chromatin accessibility. Genome-wide DNase I analysis and ChIP-seq were used to assess, respectively, chromatin accessibility and GR binding at high resolution before and after treatment with the synthetic GC dexamethasone. This revealed that preexisting accessibility of the chromatin largely but not completely determines genomic occupancy of GR [57]. It is of interest to identify also at which loci the GR can induce chromatin opening by itself, rather than binding at preexisting accessible regions.

\section{Steroid Receptor-Associated Coregulatory Complexes}

Epigenetic remodelers and chromatin context have a critical role in determining the transcriptional outcome, and therefore the directionality and intensity of gene expression changes. However, gene regulation also relies on the complex formation of GR with coregulatory partners [49]. GR transcription complexes typically consist of approximately 10 different coregulators, either stably or dynamically associated with each other $[49,58]$. Tens of transcriptional coregulators are known to interact with GR, resulting in a large variety of transcriptional complexes that lead to highly diverse gene expression outcomes [59]. For example, the members of the steroid receptor coactivator (SRC) family are transcriptional coregulators that are differentially expressed in the brain, particularly the hippocampus, the cortex, and the hypo-

Selective Glucocorticoid Receptor

Modulation in the Brain thalamus [60]. Knockout of SRC-1 is associated with disturbed regulation of important GR targets: Pomc in the pituitary [61] and Crh, both in the hypothalamus and amygdala $[62,63]$. It has been shown that the absence of SRC-coding genes NCoA2 and NCoA3 (Nuclear Coactivator 2 and 3 ) had opposite effects on anxiety responses. Female NCoA 2 knockout mice demonstrated decreased anxiety-like behavior, while $\mathrm{NCoA} 3$ knockout increased it. The latter data suggest that loss of SRC function underlies changes in behavioral phenotypes, but it is still unclear which steroid receptor pathways are involved in these effects as the coregulators affect several steroid receptors [64]. The coregulators may thus be viewed as integrators of multiple steroid signals. In a recent study, region-dependent expression of 62 coregulators and coexpression with all steroid receptors were described in the brain [65] (Fig. 1). It is clear that the coexpression of GR and MR with coregulators is dependent on the brain region. Region-dependent recruitment of coregulator proteins likely underlies the region-specific effects of steroid receptor-mediated transcription.

The substantial number of distinct GR signaling pathways and the need for specific manipulation are the basis for the category of SGRMs $[43,44,66]$. Historically, dissociated ligands bind GR and have higher efficacy at transrepressive protein-protein interactions than at transcription via GREs $[47,48]$. These types of ligands have been pursued to separate anti-inflammatory effects from unwanted metabolic side effects, but it has turned out that anti-inflammatory effects also involve GRE-dependent transcription. For example, GR activation can lead to the upregulation of I $\kappa \mathrm{B}-\alpha$ (NF- $\kappa \mathrm{B}$ inhibitor alpha), which limits the proinflammatory actions of NF- $\kappa B$ [51]. In addition, recent data suggest that inhibition of NF- $\kappa B-$ driven proinflammatory transcription may depend on GR binding to negative GREs [67]. The term "selective modulators" relates to ligands that stimulate interactions with only a subset of the GR coregulators that are recruited in the presence of full agonists $[59,68]$. Based on their selective efficacy, this class of drugs has the potential to combine agonistic and antagonistic properties in GR-mediated transcription. This may allow dissection of beneficial from adverse effects, and thus holds potential to improve current GC-based therapies. We recently discovered that the actual combination of agonism and antagonism is sometimes required to generate beneficial effects on disease outcome. To date, the best example concerns a liver steatosis disease model, in which the SGRM CORT 188335 mimicked GR agonism by stimulating lipid efflux via very low-density lipoprotein produc- 


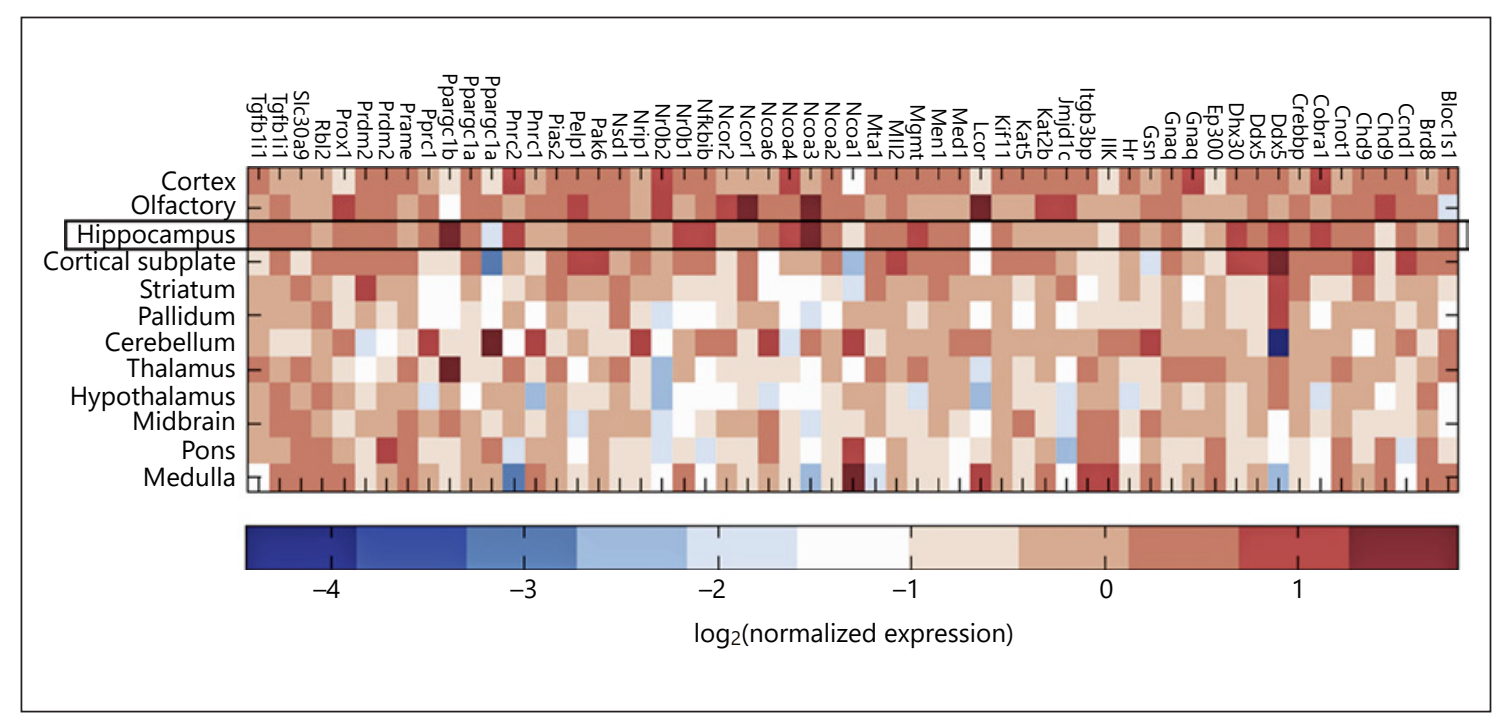

Fig. 1. Expression of nuclear receptor-associated coregulators in 12 regions of the mouse brain. The values correspond to the $\log _{2}$-transformed ratio of the average expression in each region normalized to the average of expression in the whole brain. Adapted from Mahfouz et al. [65].

tion, whereas it lacked agonist efficacy in stimulating fatty acid uptake by the liver. In this way the hepatic lipid flux was affected in such a way that efflux dominated over influx, and liver steatosis could be attenuated [69].

Although a substantial number of whole genome transcriptional and ChIP-seq datasets have been generated, it remains a major challenge to couple the extensive transcriptional outcome of GR activation to effects at the level of synaptic signaling and behavior. Comparing the effects of SGRMs on behavior, coregulator interaction, and the transcriptional signature, may help to unravel the target genes and signaling pathways underlying particular GR effects in the brain and beyond. Below, we illustrate this approach based on experiments with two recently developed SGRMs, CORT108297 and CORT118335.

\section{CORT108297 and CORT118335 in Memory,}

\section{Behavior, and Neurodegenerative Diseases}

In an attempt to understand the GC effects on memory consolidation, SGRMs CORT108297 and CORT118335 were studied in animal models. CORT108297 is a highaffinity GR ligand ( $K_{d}=0.9 \mathrm{nM}$ ) [70], while CORT118335 has a lower affinity for $\mathrm{GR}\left(K_{d}\right.$ of $\left.\sim 8 \mathrm{nM}\right)$, and shows some affinity for the MR, for which it acts as an antagonist [71]. CORT108297 was shown to have GR agonistic effects in an inhibitory avoidance memory task (Fig. 2a) [72], a paradigm known to be potentiated by GR [73] and usually set up to assess memory strength [74]. CORT118335 had opposite effects on memory consolidation as CORT118335 injection an hour before the avoidance memory task antagonized the memory-enhancing effect of corticosterone, similarly to the classical GR antagonist RU486 (Fig. 2b) [59].

In a separate study, CORT108297 was shown to decrease immobility in a forced-swim stress paradigm, which was interpreted as GR antagonist effects on depression-like behavior [75]. CORT108297 also displayed antagonist-like effects on corticosterone-induced reduction of neuronal differentiation [72], analogous to the effects of the full GR antagonist RU486 [76]. In terms of gene expression, CORT108297 was shown to act both as agonist and as antagonist, depending on the target gene [72]. A transcriptome analysis in the liver showed that in this tissue CORT118335 acts as a partial agonist on most GR target genes but lacks agonism at a, functionally important, subset of targets [69]. Both compounds are thus selective modulators, rather than classical agonists or antagonists.

CORT108297 has also been studied in models of neurodegeneration. There is a substantial association between HPA axis dysfunction and Alzheimer's disease (AD), as AD patients show elevated basal cortisol levels [77, 78]. The GR antagonist RU486 has beneficial effects in many models of $\mathrm{AD}[40,79,80]$. In a rat model of $\mathrm{AD}$, deregulation of the HPA axis is associated with cognitive impairments, apoptotic and neuroinflammatory processes, and an induction of amyloidogenic pathway. In this model, 
Fig. 2. SGRMs CORT108297 and CORT118335 act as respectively a GR agonist and a GR antagonist in memory consolidation. a Acute posttraining treatment with CORT108297 (20 mg/kg) or corticosterone $(1 \mathrm{mg} / \mathrm{kg})$ led to high retention latencies in an inhibitory avoidance task. *** $p<0.001$. Adapted from Zalachoras et al. [72]. b The administration of CORT118335 (80 mg/kg) an hour before training prevents corticosterone enhancement of memory consolidation in an inhibitory avoidance task. ${ }^{* * *} p<0.001$. Reproduced from Atucha et al. [59]. By permission of Oxford University Press on behalf of the Endocrine Society. Please visit:. https:// academic.oup.com/endo/article/156/ $11 / 4105 / 2422854$. This figure is not included under the (CC/OA license) license of this publication. For permissions, please email: journals.permissions@oup.com.

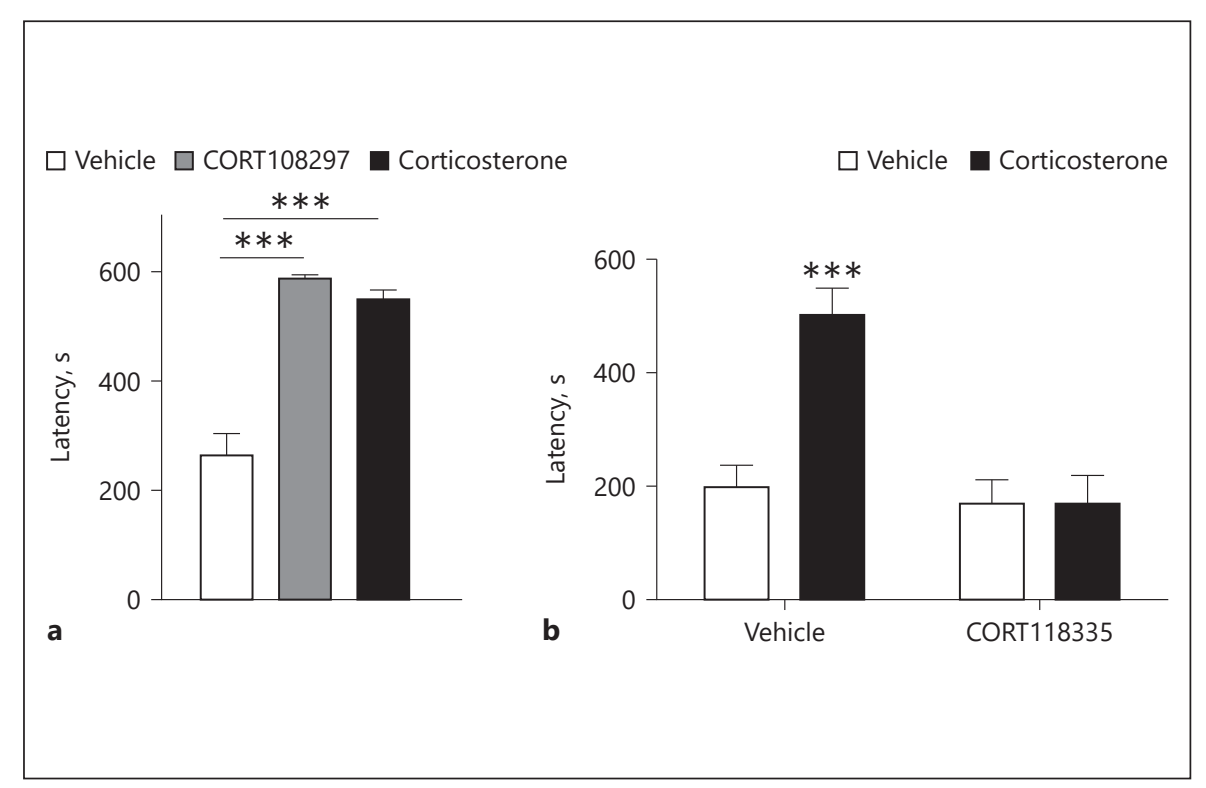

CORT108297 treatment restored synaptic markers in the hippocampus and cognitive function in spatial short-term memory [81]. CORT108297 also restored hippocampal integrity and normalized neurogenesis in the dentate gyrus in mutant Wobbler mice as a model for human amyotrophic lateral sclerosis [82]. These mice also show motoneuron degeneration, motor deficits, astrogliosis and microgliosis in the spinal cord, which are correlated with increased levels of corticosterone in plasma, brain and spinal cord. In these two neurodegenerative pathologic models it is likely that the antagonistic properties of selective modulators are mainly responsible for the beneficial effects. Indeed, the full GR selective antagonist CORT113176 also rescued the phenotype of mutant Wobbler mice [83].

\section{Differential GR Coregulator Recruitment and Gene Expression}

The differential agonistic and antagonistic effects of CORT118335 and CORT108297 on various processes likely relate to their differential effects on gene expression that in turn depend on distinct coregulator recruitment by the ligand-bound GR. Differential GR-coregulator interaction profiles for CORT118335 and CORT108297 were demonstrated via the Microarray Assay for Real-time Coregulator-Nuclear receptor Interaction (MARCoNI) technology [58], which measures in vitro interactions between the GR ligand binding domain and peptides containing the coregulator domains that are responsible for interactions with the GR (LxxLL motif containing Nuclear Re- ceptor [NR] boxes) $[84,85]$. The GR interaction profiles in the presence of SGRMs can in this way be compared with those of full GR agonists (cortisol, dexamethasone) and antagonists (mifepristone) [72].

As an example, SRC-1 is a GR coregulator associated with HPA axis function and the regulation of specific GR target genes [62]. The involvement of SRC-1 in negative feedback regulation of the HPA axis is complex due to the fact that there are two splice variants, SRC-1A and SRC1E. They share three NR boxes, but SRC-1A has an additional NR-box in the C-terminal part of the protein [86]. Moreover, SRC-1A is highly expressed in the pituitary and the hypothalamus, whereas both factors seem to be equally expressed in many other brain regions. This implies that there is a "targetable" GR-NR-box interaction that is specific for the hypothalamus and the pituitary [61].

CORT108297 differentiates GR interactions with the two SRC-1 splice variants as it preferentially induces an interaction between GR ligand binding domain and the SRC-1A NR-box 4 in the MARCoNI assay. The full agonist dexamethasone does not show any preference for SRC-1 NR-boxes [72]. These observations suggest that CORT108297 selective effects on gene expression could be based on its potential to induce specific interactions between GR and the SRC-1 coregulator NR-box 4. This notion seems to hold, as CORT108297 could differentiate between regulation of $\mathrm{Crh}$ transcription in the hypothalamus (agonism) and the central nucleus of the amygdala (no agonism) [72]. 
Fig. 3. CORT108297 and CORT118335 induce GR binding to coregulators in an intermediate fashion compared to dexamethasone and RU486. Each column represents a unique coregulator-derived peptide from a range of 50 nuclear receptor coregulators. In the MARCoNI analysis, the peptides were immobilized on a solid support and incubated with cell lysates containing tagged-GR, a ligand (dexamethasone, CORT108297, CORT118335, or RU486), and a tag-specific antibody coupled with a fluorophore. The relative interaction between each peptide and the GR was assessed by detecting the fluorescent label. The modulation index represents the $\log _{10}$-transformed ratio of the normalized fluorescence value. The values were normalized to the values obtained in control conditions (with dimethyl sulfoxide treatment) [unpubl. data].

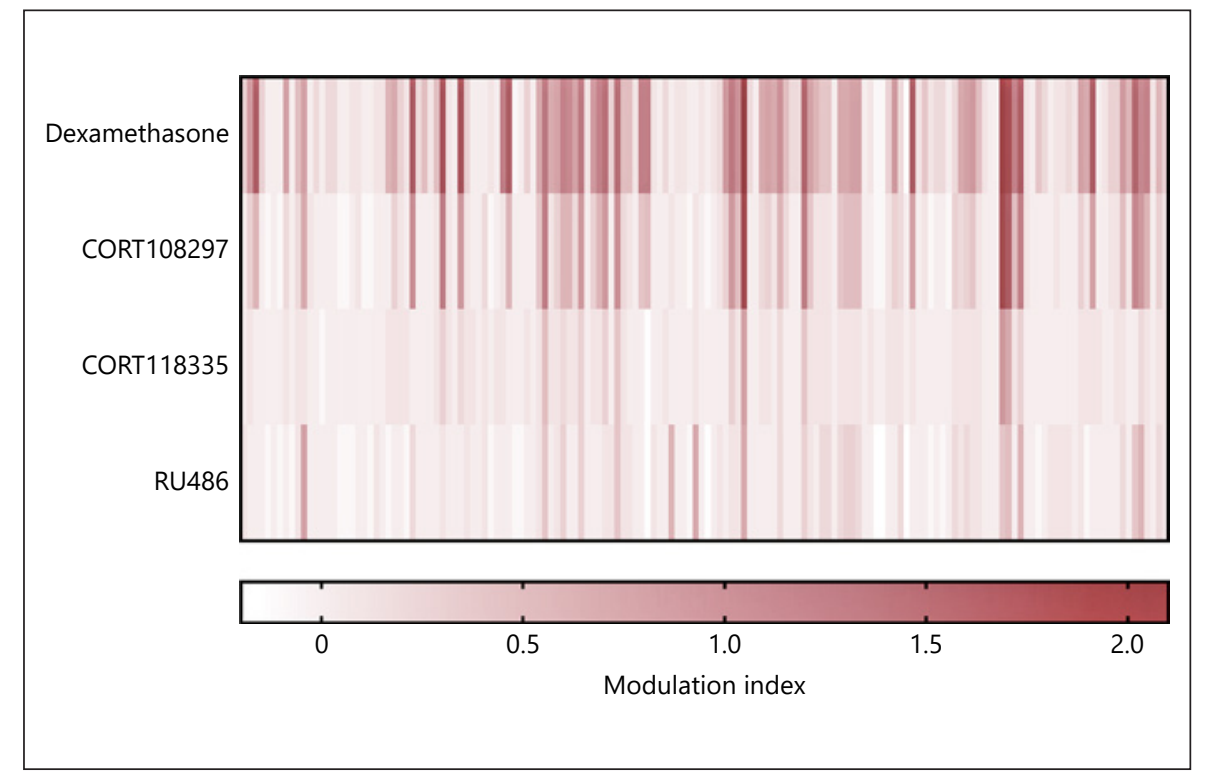

The GR coregulator interactions that are induced upon binding of CORT108297 and CORT118335 are both intermediate between those seen as full agonists (dexamethasone) and full antagonists (RU486). These SGRM-induced coregulator interaction profiles show partial overlap, but also clear differences [59, 72] (Fig. 3). Specifically, among 155 NR-boxes, 40 were shared between CORT118335, CORT108297, and dexamethasone, which likely represent shared agonistic properties. For a number of motifs, CORT118335 displayed agonist-like or antagonist-like GR interactions that were not present for CORT108297 [59].

It is an attractive hypothesis to relate functional differences to the coregulator interactions. The number of differential interactions of GR bound CORT108297 and CORT118335 provides a short-list of responsible signaling pathways. Likewise, motifs that differ between CORT108297, CORT118335, RU486 on one hand and full agonists on the other, may point to coregulators that underlie the GR-mediated aggravation of neurodegenerative processes and cognitive impairments.

Those coregulators that are differentially recruited after CORT108297 or CORT118335 binding to the GR may explain the functional differences between the compounds [59]. Comparisons between SGRMs in terms of coregulator interactions with GR and the resulting functional effects may allow the linking of particular signaling pathways with more integrative consequences, especially in the brain, where several cognitive and behavioral functions are regulated by GCs.

\section{Conclusion and Perspectives}

In conclusion, GR-mediated transcription depends on several parameters including chromatin accessibility, DNA-binding configuration, interaction with other transcription factors, and GR coregulator interactome. These parameters are highly context-dependent and differ according to the tissue, cell type, physiological state, and GR ligand. Ligand-related changes that are reflected in behavior, particularly in memory consolidation, could rely on variations in GR coregulator interactome in the hippocampus and the other limbic structures involved in memory. The combination of behavioral and transcriptional effects of SGRMs - with knowledge about their induced GR coregulatory interactome, and the cell-specific coexpression of potentially interacting partners [65] represents an interesting new research strategy to identify molecular pathways that are responsible for adaptive and maladaptive effects of GCs on brain function (Fig. 4).

Future work may include validation of these putative interactions by using coimmunoprecipitation and ChIPseq directed towards the identified coregulators and GR, either in mixed cell populations or at the single-cell level in order to characterize the cells functionally involved in the observed changes in learning and memory. It is important to consider that the integration of the simultaneous levels of modulation represents a substantial challenge. The coregulators only represent one level of GR transcriptional modulation, and it would be of interest to also investigate the nucleosome configuration, chromatin 


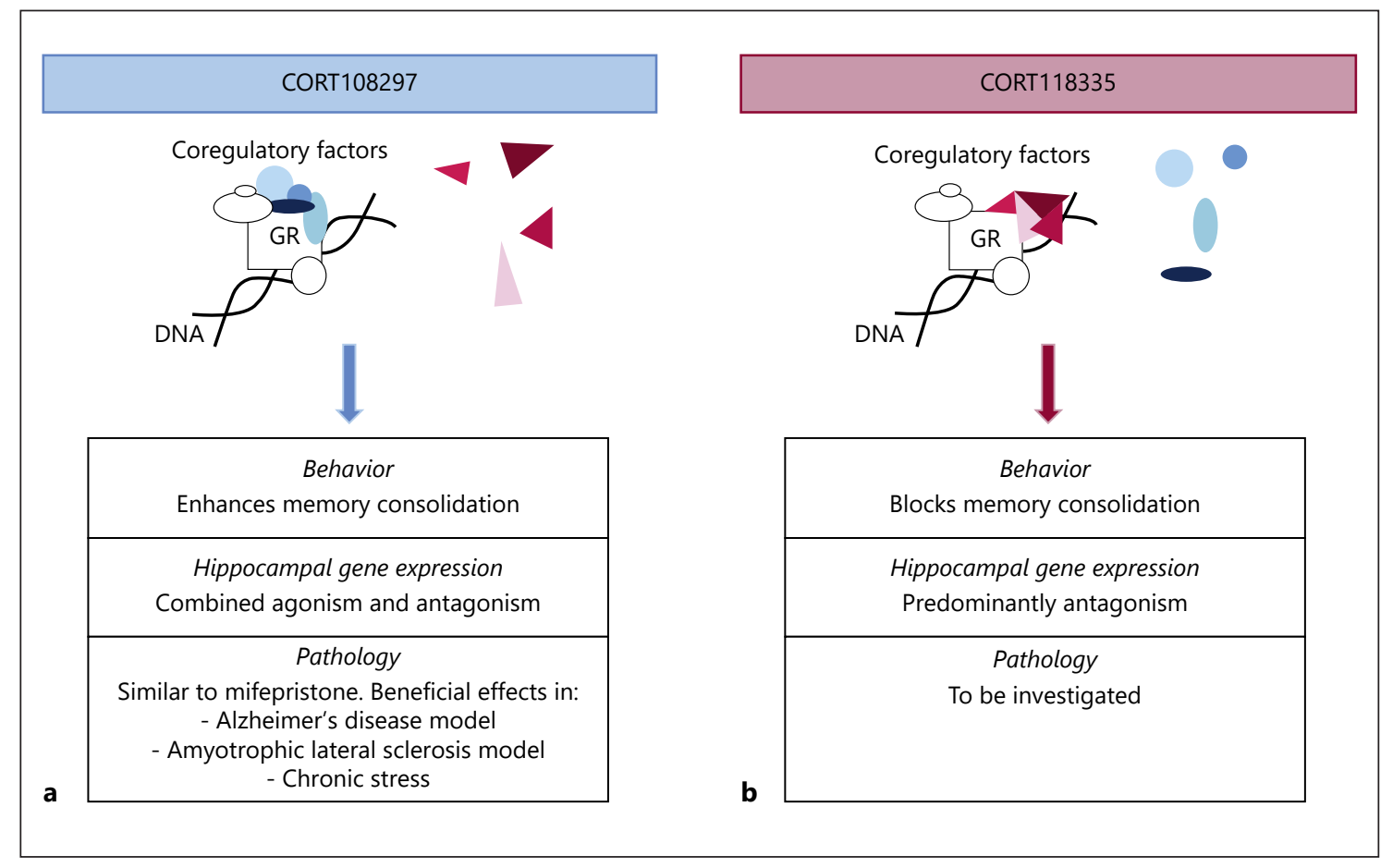

Fig. 4. SGRMs lead to differential recruitment of GR regulatory elements in the brain, as schematically depicted for CORT108297 and CORT118335. a GR agonistic-like interactions promoted in the CORT108297 context may underlie beneficial effects in memory consolidation. b GR antagonistic-like interactions promoted in the CORT118335 context may be responsible for the antagonism of GR-mediated memory consolidation.

accessibility, other transcription factors, or posttranslational modifications of the interacting effectors.

Beyond their fundamental input, SGRMs also hold potential therapeutic value in GC-related disorders of the nervous system and beyond. Some authors have suggested superior effects of selective modulators over pure antagonists [81]. GR selectivity over other steroid receptors is the first asset of SGRMs, as it prevents side effects related to androgen receptor, progesterone receptor, or even MR activities (although CORT118335 does act as a low-affinity MR antagonist). Furthermore, the other major advantage of SGRMs is the specificity regarding their agonistic and antagonistic properties according to the cell type or transcriptional target, which provides targeting of only a subset of processes. For neurodegenerative diseases, it appears that residual GC anti-inflammatory efficacy combined with antagonism on classical neuroendangerment may represent the ideal SGRM properties [83]. The application of the GR coregulator interactome hypothesis in these models will also allow the dissection of GR-mediated effects and the potential benefits of selective GR modulation compared to GR antagonism or agonism.

Selective Glucocorticoid Receptor Modulation in the Brain
The ultimate goal for this line of research is to identify the GR-mediated transcriptional effects that are responsible for adaptive processes and for brain disorders or pathologies, and to evaluate therapeutic targeting of the latter pathways.

\section{Disclosure Statement}

This research was partly funded by Corcept Therapeutics who develop new GR ligands. H.J.H. is an employee of Corcept Therapeutics. R.H. is an employee of PamGene BV.

\section{Funding Sources}

NWO/ALW (Netherlands Organization for Scientific Research), NWO-ZonMw, Board of Directors of the LUMC.

\section{Author Contributions}

Conception and design: O.C.M., J.K., J.C.B., E.M.G.V. Study supervision: O.C.M., J.K. Acquisition of data: R.H., A.M., J.C.B., E.M.G.V. Writing of the manuscript: O.C.M., J.K., E.M.G.V. Review of the manuscript: O.C.M., J.K., J.C.B., H.J.H., L.T.C.M.v.W., L.L.K., A.M. 


\section{References}

1 Smith SM, Vale WW. The role of the hypothalamic-pituitary-adrenal axis in neuroendocrine responses to stress. Dialogues Clin Neurosci. 2006;8(4):383-95.

2 Lightman SL, Conway-Campbell BL. The crucial role of pulsatile activity of the HPA axis for continuous dynamic equilibration. Nat Rev Neurosci. 2010 Oct;11(10):710-8.

3 Oakley RH, Cidlowski JA. The biology of the glucocorticoid receptor: new signaling mechanisms in health and disease. J Allergy Clin Immunol. 2013 Nov;132(5):1033-44.

4 Joëls M. Corticosteroids and the brain. J Endocrinol. 2018 Sep;238(3):R121-30.

5 Munck A, Guyre PM, Holbrook NJ. Physiological functions of glucocorticoids in stress and their relation to pharmacological actions. Endocr Rev. 1984;5(1):25-44.

6 Sapolsky RM. Stress hormones: good and bad. Neurobiol Dis. 2000 Oct;7(5):540-2.

7 Marques AH, Silverman MN, Sternberg EM. Glucocorticoid dysregulations and their clinical correlates. From receptors to therapeutics. Ann N Y Acad Sci. 2009 Oct;1179(1):1-18.

8 Fietta P, Fietta P, Delsante G. Central nervous system effects of natural and synthetic glucocorticoids. Psychiatry Clin Neurosci. 2009 Oct:63(5):613-22.

9 Liston C, Gan WB. Glucocorticoids are critical regulators of dendritic spine development and plasticity in vivo. Proc Natl Acad Sci USA. 2011 Sep;108(38):16074-9.

10 Myers B, McKlveen JM, Herman JP. Glucocorticoid actions on synapses, circuits, and behavior: implications for the energetics of stress. Front Neuroendocrinol. 2014 Apr; 35(2):180-96

11 Maroun M, Richter-Levin G. Exposure to acute stress blocks the induction of long-term potentiation of the amygdala-prefrontal cortex pathway in vivo. J Neurosci. 2003 Jun; 23(11):4406-9.

12 Richter-Levin G, Maroun M. Stress and amygdala suppression of metaplasticity in the medial prefrontal cortex. Cereb Cortex. 2010 Oct;20(10):2433-41.

13 Magariños AM, McEwen BS, Flügge G, Fuchs E. Chronic psychosocial stress causes apical dendritic atrophy of hippocampal CA3 pyramidal neurons in subordinate tree shrews. J Neurosci. 1996 May; 16(10):3534-40.

14 Watanabe Y, Gould E, McEwen BS. Stress induces atrophy of apical dendrites of hippocampal CA3 pyramidal neurons. Brain Res. 1992 Aug;588(2):341-5.

15 Radley JJ, Rocher AB, Miller M, Janssen WG Liston C, Hof PR, et al. Repeated stress induces dendritic spine loss in the rat medial prefrontal cortex. Cereb Cortex. 2006 Mar;16(3): 313-20.

16 Radley JJ, Sisti HM, Hao J, Rocher AB, McCall $\mathrm{T}$, Hof PR, et al. Chronic behavioral stress induces apical dendritic reorganization in pyramidal neurons of the medial prefrontal cortex. Neuroscience. 2004;125(1):1-6.
17 Wellman CL. Dendritic reorganization in pyramidal neurons in medial prefrontal cortex after chronic corticosterone administration. J Neurobiol. 2001 Nov;49(3):245-53.

18 Mitra R, Sapolsky RM. Acute corticosterone treatment is sufficient to induce anxiety and amygdaloid dendritic hypertrophy. Proc Natl Acad Sci USA. 2008 Apr;105(14):5573-8.

19 de Kloet ER, Joëls M, Holsboer F. Stress and the brain: from adaptation to disease. Nat Rey Neurosci. 2005 Jun;6(6):463-75.

20 Reul JM, de Kloet ER. Two receptor systems for corticosterone in rat brain: microdistribution and differential occupation. Endocrinology. 1985 Dec;117(6):2505-11.

21 Hodge RD, Bakken TE, Miller JA, Smith KA, Barkan ER, Graybuck LT, et al. Conserved cell types with divergent features between human and mouse cortex. bioRxiv. 2018. https://doi. org/10.1101/384826.

22 Cembrowski MS, Wang L, Sugino K, Shields BC, Spruston N. Hipposeq: a comprehensive RNA-seq database of gene expression in hippocampal principal neurons. eLife. $2016 \mathrm{Apr}$ 5:e14997.

23 Saunders A, Macosko E, Wysoker A, Goldman M, Krienen F, Bien E, et al. A Single-Cell Atlas of Cell Types, States, and Other Transcriptional Patterns from Nine Regions of the Adult Mouse Brain. bioRxiv. 2018. https:// doi.org/10.1101/299081.

24 Oitzl MS, de Kloet ER. Selective corticosteroid antagonists modulate specific aspects of spatial orientation learning. Behav Neurosci. 1992 Feb;106(1):62-71.

25 Oitzl MS, Reichardt HM, Joëls M, de Kloet ER. Point mutation in the mouse glucocorticoid receptor preventing DNA binding impairs spatial memory. Proc Natl Acad Sci USA. 2001 Oct;98(22):12790-5.

26 Sarabdjitsingh RA, Jezequel J, Pasricha N, Mikasova L, Kerkhofs A, Karst H, et al. Ultradian corticosterone pulses balance glutamatergic transmission and synaptic plasticity. Proc Natl Acad Sci USA. 2014 Sep;111(39):1426570.

27 Karst H, Joëls M. Corticosterone slowly enhances miniature excitatory postsynaptic current amplitude in mice CA1 hippocampal cells. J Neurophysiol. 2005 Nov;94(5):347986.

28 Joëls M, Sarabdjitsingh RA, Karst H. Unraveling the time domains of corticosteroid hormone influences on brain activity: rapid, slow, and chronic modes. Pharmacol Rev. 2012 Oct;64(4):901-38.

29 Roozendaal B, Griffith QK, Buranday J, De Quervain DJ, McGaugh JL. The hippocampus mediates glucocorticoid-induced impairment of spatial memory retrieval: dependence on the basolateral amygdala. Proc Natl Acad Sci USA. 2003 Feb;100(3):1328-33.
30 Ouanes S. Glucocorticoid-based therapeutic options for PTSD. Eur Psychiatry. 2016; 33:S215.

31 de Quervain DJ, Bentz D, Michael T, Bolt OC, Wiederhold BK, Margraf J, et al. Glucocorticoids enhance extinction-based psychotherapy. Proc Natl Acad Sci USA. 2011 Apr; 108(16):6621-5.

32 Pufall MA. Glucocorticoids and Cancer. Adv Exp Med Biol. 2015;872:315-33.

33 Solano JM, Jacobson L. Glucocorticoids reverse leptin effects on food intake and body fat in mice without increasing NPY mRNA. Am J Physiol. 1999 Oct;277(4):E708-16.

34 Joëls M. Impact of glucocorticoids on brain function: relevance for mood disorders. Psychoneuroendocrinology. 2011 Apr;36(3): 406-14.

35 Meijer OC, de Kloet ER. A Refill for the Brain Mineralocorticoid Receptor: The Benefit of Cortisol Add-On to Dexamethasone Therapy. Endocrinology. 2017 Mar;158(3):448-54.

36 Warris LT, van den Heuvel-Eibrink MM, Ariës IM, Pieters R, van den Akker EL, den Boer ML. Hydrocortisone does not influence glucocorticoid sensitivity of acute lymphoblastic leukemia cells. Haematologica. 2015 Apr;100(4):e137-9.

37 Belanoff JK, Rothschild AJ, Cassidy F, DeBattista C, Baulieu EE, Schold C, et al. An open label trial of C-1073 (mifepristone) for psychotic major depression. Biol Psychiatry. 2002 Sep;52(5):386-92.

38 Gallagher P, Young AH. Mifepristone (RU486) treatment for depression and psychosis: a review of the therapeutic implications. Neuropsychiatr Dis Treat. 2006 Mar;2(1):33-42.

39 Vendruscolo LF, Estey D, Goodell V, Macshane LG, Logrip ML, Schlosburg JE, et al. Glucocorticoid receptor antagonism decreases alcohol seeking in alcohol-dependent individuals. J Clin Invest. 2015 Aug;125(8):31937.

40 Green KN, Billings LM, Roozendaal B, McGaugh JL, LaFerla FM. Glucocorticoids increase amyloid-beta and tau pathology in a mouse model of Alzheimer's disease. J Neurosci. 2006 Aug;26(35):9047-56.

41 Spiga F, Knight DM, Droste SK, ConwayCampbell B, Kershaw Y, MacSweeney CP, et al. Differential effect of glucocorticoid receptor antagonists on glucocorticoid receptor nuclear translocation and DNA binding. Psychopharmacol. 2011 Feb;25(2):211-21.

42 Spiga F, Harrison LR, Wood SA, Atkinson HC, MacSweeney CP, Thomson F, et al. Effect of the glucocorticoid receptor antagonist Org 34850 on basal and stress-induced corticosterone secretion. J Neuroendocrinol. $2007 \mathrm{Nov}$ 19(11):891-900

43 De Bosscher K, Vanden Berghe W, Beck IM, Van Molle W, Hennuyer N, Hapgood J, et al. A fully dissociated compound of plant origin for inflammatory gene repression. Proc Natl Acad Sci USA. 2005 Nov; 102(44):15827-32. 
44 Meijer OC, Koorneef LL, Kroon J. Glucocorticoid receptor modulators. Ann Endocrinol (Paris). 2018 Jun;79(3):107-11.

45 Groeneweg FL, Karst H, de Kloet ER, Joëls M. Rapid non-genomic effects of corticosteroids and their role in the central stress response. J Endocrinol. 2011 May;209(2):153-67.

46 Weikum ER, Knuesel MT, Ortlund EA, Yamamoto KR. Glucocorticoid receptor control of transcription: precision and plasticity via allostery. Nat Rev Mol Cell Biol. 2017 Mar; 18(3):159-74.

47 Surjit M, Ganti KP, Mukherji A, Ye T, Hua G, Metzger D, et al. Widespread negative response elements mediate direct repression by agonist-liganded glucocorticoid receptor. Cell. 2011 Apr;145(2):224-41.

48 Hudson WH, Youn C, Ortlund EA. The structural basis of direct glucocorticoid-mediated transrepression. Nat Struct Mol Biol. 2013 Jan;20(1):53-8.

49 O'Malley BW, Malovannaya A, Qin J. Minireview: nuclear receptor and coregulator proteomics-2012 and beyond. Mol Endocrinol. 2012 Oct;26(10):1646-50.

50 Martens C, Bilodeau S, Maira M, Gauthier Y, Drouin J. Protein-protein interactions and transcriptional antagonism between the subfamily of NGFI-B/Nur77 orphan nuclear receptors and glucocorticoid receptor. Mol Endocrinol. 2005 Apr;19(4):885-97.

51 De Bosscher K, Van Craenenbroeck K, Meijer OC, Haegeman G. Selective transrepression versus transactivation mechanisms by glucocorticoid receptor modulators in stress and immune systems. Eur J Pharmacol. 2008 Apr; 583(2-3):290-302.

52 Heck S, Kullmann M, Gast A, Ponta $\mathrm{H}$, Rahmsdorf HJ, Herrlich P, et al. A distinct modulating domain in glucocorticoid receptor monomers in the repression of activity of the transcription factor AP-1. EMBO J. 1994 Sep;13(17):4087-95.

53 Polman JA, de Kloet ER, Datson NA. Two populations of glucocorticoid receptor-binding sites in the male rat hippocampal genome. Endocrinology. 2013 May;154(5):1832-44.

54 Pooley JR, Flynn BP, Grøntved L, Baek S, Guertin MJ, Kershaw YM, et al. GenomeWide Identification of Basic Helix-Loop-Helix and NF-1 Motifs Underlying GR Binding Sites in Male Rat Hippocampus. Endocrinology. 2017 May;158(5):1486-501.

55 van Weert LT, Buurstede JC, Mahfouz A, Braakhuis PS, Polman JA, Sips HC, et al. NeuroD Factors Discriminate Mineralocorticoid From Glucocorticoid Receptor DNA Binding in the Male Rat Brain. Endocrinology. 2017 May;158(5):1511-22.

56 Mifsud KR, Reul JM. Mineralocorticoid and glucocorticoid receptor-mediated control of genomic responses to stress in the brain Stress. 2018 Sep;21(5):389-402.
57 John S, Sabo PJ, Thurman RE, Sung MH, Biddie SC, Johnson TA, et al. Chromatin accessibility pre-determines glucocorticoid receptor binding patterns. Nat Genet. 2011 Mar; 43(3):264-8.

58 Desmet SJ, Dejager L, Clarisse D, Thommis J, Melchers D, Bastiaensen N, et al. Cofactor profiling of the glucocorticoid receptor from a cellular environment. Methods Mol Biol. 2014;1204:83-94.

59 Atucha E, Zalachoras I, van den Heuvel JK, van Weert LT, Melchers D, Mol IM, et al. A Mixed Glucocorticoid/Mineralocorticoid Selective Modulator With Dominant Antagonism in the Male Rat Brain. Endocrinology. 2015 Nov; 156(11):4105-14.

60 Meijer OC, Steenbergen PJ, De Kloet ER. Differential expression and regional distribution of steroid receptor coactivators SRC-1 and SRC-2 in brain and pituitary. Endocrinology. 2000 Jun;141(6):2192-9.

61 Winnay JN, Xu J, O'Malley BW, Hammer GD. Steroid receptor coactivator-1-deficient mice exhibit altered hypothalamic-pituitaryadrenal axis function. Endocrinology. 2006 Mar;147(3):1322-32.

62 Lachize S, Apostolakis EM, van der Laan S, Tijssen AM, Xu J, de Kloet ER, et al. Steroid receptor coactivator- 1 is necessary for regulation of corticotropin-releasing hormone by chronic stress and glucocorticoids. Proc Natl Acad Sci USA. 2009 May; 106(19):8038-42.

63 Zalachoras I, Verhoeve SL, Toonen LJ, van Weert LT, van Vlodrop AM, Mol IM, et al. Isoform switching of steroid receptor co-activator-1 attenuates glucocorticoid-induced anxiogenic amygdala CRH expression. Mol Psychiatry. 2016 Dec;21(12):1733-9.

64 Stashi E, Wang L, Mani SK, York B, O’Malley BW. Research resource: loss of the steroid receptor coactivators confers neurobehavioral consequences. Mol Endocrinol. 2013 Oct; 27(10):1776-87.

65 Mahfouz A, Lelieveldt BP, Grefhorst A, van Weert LT, Mol IM, Sips HC, et al. Genomewide coexpression of steroid receptors in the mouse brain: identifying signaling pathways and functionally coordinated regions. Proc Natl Acad Sci USA. 2016 Mar;113(10):273843.

66 Heier CR, Damsker JM, Yu Q, Dillingham BC, Huynh T, Van der Meulen JH, et al. VBP15, a novel anti-inflammatory and membrane-stabilizer, improves muscular dystrophy without side effects. EMBO Mol Med. 2013 Oct;5(10):1569-85.

67 Hudson WH, Vera IM, Nwachukwu JC, Weikum ER, Herbst AG, Yang Q, et al. Cryptic glucocorticoid receptor-binding sites pervade genomic NF- $\kappa \mathrm{B}$ response elements. Nat Commun. 2018 Apr;9(1):1337.

68 Coghlan MJ, Jacobson PB, Lane B, Nakane M, Lin CW, Elmore SW, et al. A novel antiinflammatory maintains glucocorticoid efficacy with reduced side effects. Mol Endocrinol. 2003 May; 17(5):860-9.
69 Koorneef LL, van den Heuvel JK, Kroon J, Boon MR, 't Hoen PA, Hettne KM, et al. Selective glucocorticoid receptor modulation prevents and reverses nonalcoholic fatty liver disease in male mice. Endocrinology. 2018 Dec;159(12):3925-36.

70 Clark RD, Ray NC, Williams K, Blaney P, Ward S, Crackett PH, et al. 1H-Pyrazolo[3,4g] hexahydro-isoquinolines as selective glucocorticoid receptor antagonists with high functional activity. Bioorg Med Chem Lett. 2008 Feb;18(4):1312-7.

71 Hunt HJ, Ray NC, Hynd G, Sutton J, Sajad M, O'Connor E, et al. Discovery of a novel nonsteroidal GR antagonist with in vivo efficacy in the olanzapine-induced weight gain model in the rat. Bioorg Med Chem Lett. 2012 Dec; 22(24):7376-80.

72 Zalachoras I, Houtman R, Atucha E, Devos R, Tijssen AM, Hu P, et al. Differential targeting of brain stress circuits with a selective glucocorticoid receptor modulator. Proc Natl Acad Sci USA. 2013 May;110(19):7910-5.

73 Fornari RV, Wichmann R, Atucha E, Desprez T, Eggens-Meijer E, Roozendaal B. Involvement of the insular cortex in regulating glucocorticoid effects on memory consolidation of inhibitory avoidance training. Front Behav Neurosci. 2012 Mar;6:10.

74 Atucha E, Roozendaal B. The inhibitory avoidance discrimination task to investigate accuracy of memory. Front Behav Neurosci. 2015 Mar;9:60.

75 Solomon MB, Wulsin AC, Rice T, Wick D, Myers B, McKlveen J, et al. The selective glucocorticoid receptor antagonist CORT 108297 decreases neuroendocrine stress responses and immobility in the forced swim test. Horm Behav. 2014 Apr;65(4):363-71.

76 Mayer JL, Klumpers L, Maslam S, de Kloet ER, Joëls M, Lucassen PJ. Brief treatment with the glucocorticoid receptor antagonist mifepristone normalises the corticosterone-induced reduction of adult hippocampal neurogenesis. J Neuroendocrinol. 2006 Aug;18(8):629_ 31.

77 Hoogendijk WJG, Meynen G, Endert E, Hofman MA, Swaab DF. Increased cerebrospinal fluid cortisol level in Alzheimer's disease is not related to depression. Neurobiol Aging. 2006;27(5):780.e1-.e2.

78 Csernansky JG, Dong H, Fagan AM, Wang L, Xiong C, Holtzman DM, et al. Plasma cortisol and progression of dementia in subjects with Alzheimer-type dementia. Am J Psychiatry. 2006 Dec;163(12):2164-9.

79 Baglietto-Vargas D, Medeiros R, MartinezCoria H, LaFerla FM, Green KN. Mifepristone alters amyloid precursor protein processing to preclude amyloid beta and also reduces tau pathology. Biol Psychiatry. 2013 Sep;74(5):357-66.
Selective Glucocorticoid Receptor

Modulation in the Brain
Neuroendocrinology 2019;109:266-276 DOI: $10.1159 / 000499659$ 
80 Lesuis SL, Weggen S, Baches S, Lucassen PJ, Krugers HJ. Targeting glucocorticoid receptors prevents the effects of early life stress on amyloid pathology and cognitive performance in APP/PS1 mice. Transl Psychiatry. 2018 Mar;8(1):53.

81 Pineau F, Canet G, Desrumaux C, Hunt H, Chevallier N, Ollivier M, et al. New selective glucocorticoid receptor modulators reverse amyloid- $\beta$ peptide-induced hippocampus toxicity. Neurobiol Aging. 2016 Sep;45:10922.
82 Meyer M, Gonzalez Deniselle MC, Hunt H, de Kloet ER, De Nicola AF. The selective glucocorticoid receptor modulator CORT108297 restores faulty hippocampal parameters in Wobbler and corticosterone-treated mice. J Steroid Biochem Mol Biol. 2014 Sep;143:40-8.

83 Meyer M, Lara A, Hunt H, Belanoff J, de Kloet ER, Gonzalez Deniselle MC, et al. The Selective Glucocorticoid Receptor Modulator Cort 113176 Reduces Neurodegeneration and Neuroinflammation in Wobbler Mice Spinal Cord. Neuroscience. 2018 Aug;384:384-96.

84 Broekema MF, Hollman DA, Koppen A, van den Ham HJ, Melchers D, Pijnenburg D, et al. Profiling of 3696 Nuclear Receptor-Coregulator Interactions: A Resource for Biological and Clinical Discovery. Endocrinology. 2018 Jun;159(6):2397-407.
85 Koppen A, Houtman R, Pijnenburg D, Jeninga EH, Ruijtenbeek R, Kalkhoven E. Nuclear receptor-coregulator interaction profiling identifies TRIP3 as a novel peroxisome proliferator-activated receptor gamma cofactor. Mol Cell Proteomics. 2009 Oct;8(10):221226.

86 Kalkhoven E, Valentine JE, Heery DM, Parker MG. Isoforms of steroid receptor co-activator 1 differ in their ability to potentiate transcription by the oestrogen receptor. EMBO J. 1998 Jan;17(1):232-43. 